Using artifacts in brainstorming sessions to secure participation and decouple sequentiality

Nielsen, Mie Femø

Published in:

Discourse Studies

Publication date:

2012

Document version

Publisher's PDF, also known as Version of record

Citation for published version (APA):

Nielsen, M. F. (2012). Using artifacts in brainstorming sessions to secure participation and decouple sequentiality. Discourse Studies, 14(1), 87-109. http://dis.sagepub.com/content/14/1/87.full.pdf+html 


\title{
Using artifacts in brainstorming sessions to secure participation and decouple sequentiality
}

\section{Mie Femø Nielsen}

University of Copenhagen, Denmark

\begin{abstract}
This article discusses 'brainstorm' interaction in a multimodal perspective. It shows how an innovation workshop facilitator is 'doing facilitation' by not only organizing group activities and managing turntaking, but also drawing each group member out to participate actively and contribute to the group process. Institutional goals are transformed to individual conversational participation. Participants are helped to express their thoughts and engage in a social process of clarifying, developing and refining ideas. In the process the facilitator is socializing the participants into a particular participation framework, letting them collaborate in shaping a local community of practice. The facilitator is separating phases of activities to afford decoupling actions, creating specific local sequential environments for participants to produce particular kinds of talk, thus engaging a group of participants in a social process of collaborative idea development. The article will show how multimodal orientation to a range of semiotic resources (whiteboard, colored cards, speed markers, re-usable adhesive putty, body posture, gestures, gazes, pauses and talk) is used to manage topical talk, elicit talk from a particular person, manage speaker transition, secure progression and shifts, perform shift in participant identity and elicit talk performing particular social actions, explanations and accounts. A process is shaped in which collaboratively produced underspecified ideas are turned into 'noticings' in order to create slots for them to be explained and accounted for so that individual cognitive processes are made available for treatment in a social process of idea development, and selection of ideas is prioritized over discussion/rejection.
\end{abstract}

\section{Keywords}

explanation slot, facilitator, group development process, innovation, multimodality, noticing, under-specification, workshop

\footnotetext{
Corresponding author:

Mie Femø Nielsen, Department of Scandinavian Studies and Linguistics, University of Copenhagen,

Njalsgade I20, DK-2300 Copenhagen, Denmark.

Email: femoe@hum.ku.dk
} 
Innovation may be seen as a process implicating waste. A study has shown how the development from 3000 raw ideas from which more than 300 collected ideas turned into 125 small projects, leading to nine market research development projects, resulted in four big projects with test production. These ended in about 1.7 commercial product launches (43 percent of the four big projects), of which only one turned out to be a success (Stevens and Burley, 1997). Such studies of idea waste have resulted in an idea development paradigm of ideas considered raw material, unpolished diamonds in the rough. In order to develop a large portion of raw ideas to feed a development process, a preliminary phase of creativity is usually organized as a first step in innovation (Amabile, 1996), including a set of activities planned for a group of participants. One of them is 'brainstorming', with the rationale that quantity increases the probability of quality and therefore building on a set of rules for the participants to follow: producing as many and as wild a group of ideas as possible, never criticizing or retracting, always building on each others' ideas, adding to them (Osborn, 1953). However, a group process may reduce the speed of contribution and the contribution frequency of individual participants, and the individual participants' mental capacity may not be able to both hold their own ideas and listen to others', leading to the loss of many potential ideas (Diehl and Stroebe, 1987; Taylor et al., 1958). Also, innovation processes have stages of divergent and convergent thinking (Guilford, 1967), broadening perspectives and opening up possibilities before refining, narrowing and making realizable. This calls for practical organization of phases, management of shifts between perspectives and focus on collecting/managing ideas.

In a larger, planned process, accomplishing the social task of innovating or developing something of strategic interest to a company or a constellation of stakeholders, a workshop may be organized as one crucial activity with a set of collaborators. Drawing metaphorically on light manual industrial work done in small establishments, workshops are seminars/ meetings emphasizing knowledge-driven postmodern workplace interaction between participants (as opposed to knowledge-driven manual labor). Workshops are a particular kind of institutional interaction; they are goal-oriented activities in settings with special constraints on what the participants will treat as allowable contributions to the business at hand, since their talk may be associated with inferential frameworks and procedures that are particular to a specific institutional context (Drew and Heritage, 1992).

\section{Broad participation as an objective and a challenge}

Putting together a group with diverse knowledge, competences, experiences, age, education, ethnicity, social status, etc., is proven to be a core factor in the advancement of innovation (Campbell, 1960; Lopez et al., 1993; Simonton, 1999; Sutton, 2002). Diversity may lead to incompatibility between participants, potentially 'fruitful when it creates the essential tension' (Runco, 1998: 176). So-called 'constructive tension' between participants may well lead to arguments, frustration and enmity. Difference and conflict, however, may drive the innovative process (Lysklett, 2007). Therefore, it may be strategically relevant to foster social tension and manage it in order to promote productive conflict in which participants feel open and confident.

Participation is not equally distributed in innovation groups. Typically, 10 percent of the participants are responsible for 50 percent of the contributions (Simonton, 1999). The 
interaction is asymmetrical with respect to participation rights and knowledge. Fear of evaluation among group members may lead to the withholding of ideas while encouraging others to free-ride (Diehl and Stroebe, 1987). Bridging asymmetries and building on the rationale of the need for diversity, an important consideration is therefore to encourage broader participation. The purpose of 'drawing people out' is to support participants in clarifying, developing, and refining their ideas, exploring what matters to them and help them express their thoughts (Kaner et al., 2007).

It is furthermore proven that sharing ideas may have a cognitively stimulating effect on the individual group member's generating of ideas, provided that their attention is directed toward the ideas of other group members (Nijstad et al., 2002). Distributed cognition is seen as a means to achieve innovation. This makes it necessary to communicate ideas in a way that is practical, visible and easy to collect, sort, categorize and archive.

\section{The need for facilitation}

Developing and managing ideas as a group process is a complex endeavor encompassing not only orientation to time constraints and to generation of idea volume, but also to participant diversity and cooperation. This brings with it a need for interaction formats allowing for distributed cognition, shifting between perspectives, securing collaboration and progression towards a satisfactory outcome. That calls for practical organization of people, phases and artifacts in order to have the interaction perceived (inside and outside the group) as productive, effective and efficient.

Therefore, leadership at process level is called for. Such process leaders are often called 'facilitators'. A facilitator is a 'content-neutral' party; an individual working to enable groups and organizations to collaborate, work more effectively and achieve synergy, or one who may assist a group in thinking deeper about its assumptions, beliefs, values, systemic processes, context, etc., in order to achieve an informal, flexible alternative to constricting formats like parliamentary procedure or 'Robert's Rules of Order' (Kaner et al., 2007). A workshop facilitator is often an external consultant, working to organize and lead events like meetings, seminars, workshops and group sessions in order to help their participants reach a certain goal or conclusion defined in advance (by the participants or the management). They are frequently used in innovation projects and change management projects; but usually not used in 'ordinary', intra-organizational idea development meetings.

Turning individual cognitive processes into collaborative social idea development processes necessitates having the individual workshop participant explain his or her ideas to the group. This article will show how a facilitator may foster such cognitive distribution, using a coordinated orientation to talk, gesture, gaze, posture, movement, direction and artifacts like whiteboards and sticky notes, as a subtle way of fostering individual participation in the development process and steering participants in a particular direction toward a desired group process outcome.

The article contributes to the micro-analytic study of authentic multimodal meetings by showing how facilitators use sticky notes or colored cards to help participants turn ideas and individual cognitive processes into 'talkables' available for the group to address. 


\section{Data}

The data in this study are from an innovation consortium with the institutional aim of developing user-driven, personal comfort in the workplace. The project involved a series of meetings and workshops organized as a set of practices of interaction shaped to facilitate this institutional aim.

The recorded data are from day 2 of workshop 1 (considered the day they should 'work'). Present at the workshop is a prototype within office furniture (not to be disclosed here). In order to further develop this prototype, a consortium of eight stakeholders (from a special area of the building industry) with different interests in the final result is gathered, each represented by one to four employees. The first workshop day consisted of participant presentations, PowerPoint presentations from different invited speakers and three site visits. On the second workshop day the participants were divided into three groups, supervised by three facilitators. This article focuses on Jørgen's group. Participants in Jørgen's group are Poul Erik, Tim, Kai and Lars.

Video recordings were made in a seminar room when all the participants were gathered for plenary sessions (four cameras) and in three group rooms (two cameras in each group room). It was prioritized for the research team not to be present in the workshop rooms. The cameras were positioned so that they would be able to catch all participants and whiteboards/flipovers, not knowing in advance what would be used when. In the data presented in this article it is therefore striking that half of the image is empty on the screen shots showing the facilitator.

Names of companies, persons and activities/work areas, which may convey or reveal any specific identities, have been rendered anonymous. The data are transcribed according to Gail Jefferson's notation system and analyzed from a multimodal conversation analytic perspective, incorporating the participants' use of a range of resources from different semiotic fields in order to produce social actions and create meaning (Goodwin, 1981, 1994, 2003, 2007; Sidnell, 2005; Stivers and Sidnell, 2005; Streeck, 1993).

This article will focus on the first exercise in the first group session. As such, it is creating the local context for the following group interaction, including other group exercises, and thus socializing the participants to this particular interaction format and potentially shaping a local community of practice. The participants have 20 minutes for the whole exercise, including all phases, before beginning a new exercise.

The participants to the interaction, especially the facilitators, voice a lot of terms and concepts (members' categories) when introducing what they are all about to do. In advance the 'facilitator' has told 'the participants' to follow a specific procedure. The 'innovation project' centers on 'personal comfort in the work place', and 'a prototype' within this field has been 'developed' and shown to the participants on the first day of the 'workshop'. Now they are told to 'start from zero' and 'develop something' regarding 'personal comfort' much 'wider' than the prototype. They are told to explore the hypothetical situation: ' if I were king, what would I develop regarding personal comfort?'. Whenever they come up with an 'idea', defined in the interaction by the facilitator as 'something they could make money on', they are to 'write it down' on a colored card. They are told to produce 'as many cards' as they can, 'one idea per card'. They are not to 'comment' on the ideas, 'just hang the cards on the whiteboard' using 'adhesive putty'. After that, they are instructed to 'look at all the cards' and to 'put them into words'. 


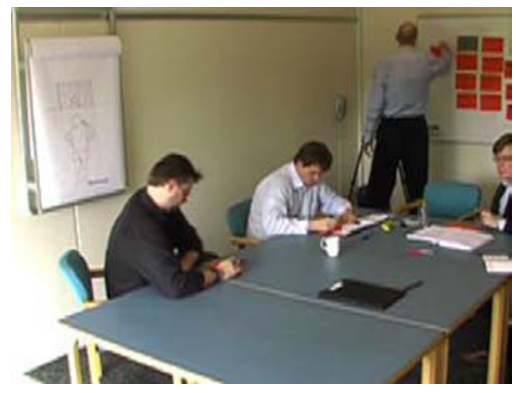

Figure I. Participants write on cards and hang them on the whiteboard with adhesive putty

The analysis takes note of this abundance of members' categories for making sense of the interaction. The analysis, however, will treat these as preliminary claims about particular implications for the interaction. The focus of analysis will be to explore if and how a process arises from the interaction between talking bodies and material things. Through the analysis of three excerpts, specific practices or conduct will be described. The conclusion of this article will focus on how the participants' conduct produces a characteristic state of affairs and it will be discussed how such interaction may serve the purpose of 'brainstorming'.

\section{Artifacts facilitating shared cognition}

In workshops, artifacts from office supply stores (speed markers, colored cards, adhesive putty, whiteboards, flipovers, wallpaper and sticky notes) play a huge role. They are introduced and used by facilitators in the process to foster shared cognition, letting the participants go from thoughts to notes, from notes to talk and from talk to other cognitive processes furthered by other talk.

The role artifacts play in collectives tends to be neglected in social sciences in general and organizational studies in particular (Cooren et al., 2006). However, important studies have been done within anthropology, micro-sociology, ethnomethodology and linguistics (e.g. Goodwin, 1994, 1997, 1999; Goodwin and Duranti, 1992; Goodwin and Goodwin, 1996; Latour, 1987, 1988; Latour and Woolgar, 1986/1979; Mondada, 2003, 2011; Whalen, 1995; Whalen et al., 2002). Things 'make us smart'; without external aids, memory, thought and reasoning are all constrained (Norman, 1993: 43). The use of material objects during institutional interaction affords cognitive actions and makes it possible to externalize internal and individual processes to enable communication (Streeck, 1996).

In the beginning of the group exercise in focus in this article, the participants are sitting at a table together silently, writing words on cards, getting up to hang them on a whiteboard on the wall, then sitting down again at the table to think and write more cards (see Figure 1).

As seen in Figure 1, the colored cards are neatly arranged in aligned rows and columns. This makes them available to the group for inspection and comparison (Streeck, 1996) and symbolically turns them into 'idea cards', containers for cognitive intent and content. The columns of cards are co-creating affordances for a group process of idea development.

In the following, three excerpts will be analyzed, and it will be shown how the multimodal orientation to a range of semiotic resources (whiteboard, colored cards, body posture, 


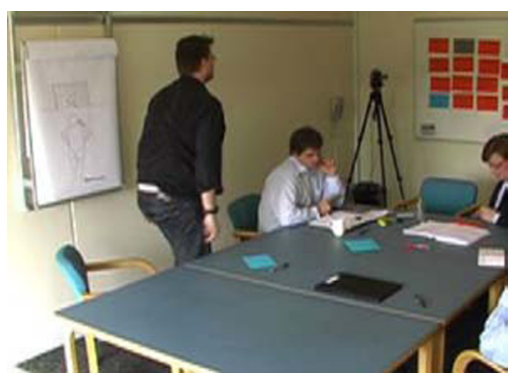

Figure 2. Facilitator gets up and moves towards the whiteboard

gestures, gazes, pauses and talk) are used to organize topical talk, manage speaker transition and shape action format into particular phases.

\section{Topic and timing}

Artifacts like whiteboards and colored cards are vital for a facilitator in order to select topic and secure timing. This is observable in the following excerpt, which is from the beginning of the first group exercise where the whiteboard and the colored cards are in use. After sitting silently with the participants at a table, writing words on colored cards and getting up to hang these cards on the whiteboard on the wall (see Figure 2), the facilitator now gets up and asks the participant to talk about the cards:

\section{Extract 1: A1 Avoid noise}

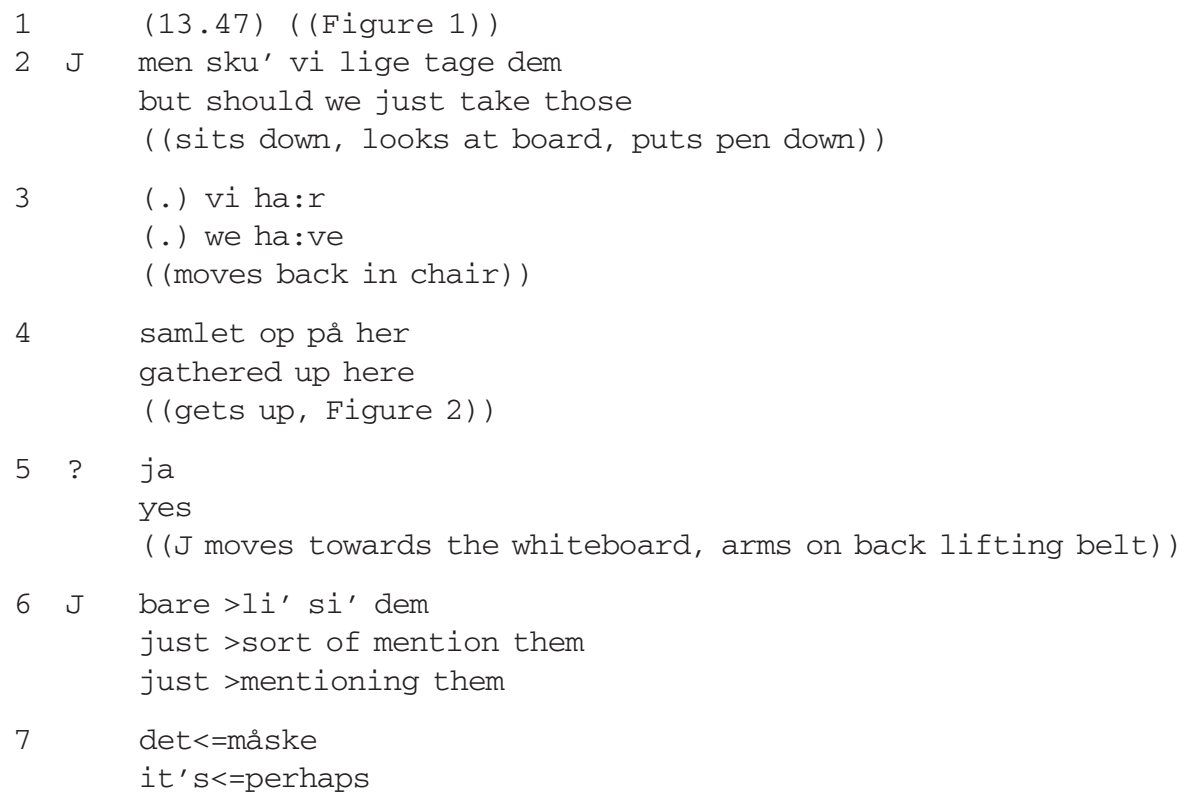



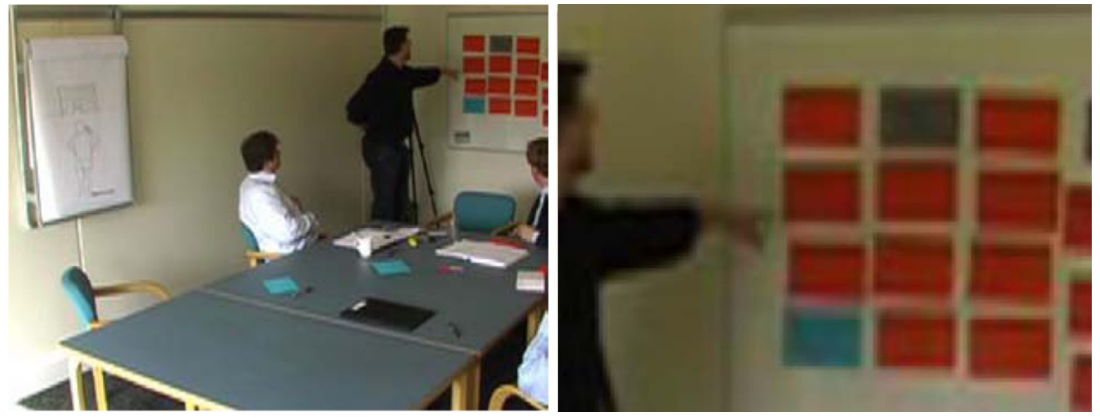

Figures $\mathbf{3 a}$ and $\mathbf{3 b}$. Jørgen points at a card

8

$>$ sæt' et par ord< på dem

$>$ put a few words< on them

$>$ put them into words

$9 \quad i k$

right

$10 \quad(2.5)$

( (everybody looks at whiteboard))

11 den her oppe

this here up

this up here

$12 \quad(0.3)$

( ( $\mathrm{J}$ moves left arm up, points at a card, Figure 3))

13 undgå st $\varnothing j$

avoid noise

( ( $\mathrm{J}$ moves finger, points a card higher up, Figure 4))

14 når jeg har behov

when I have need

when I need

( (pulls left finger/arm back, looks at card, Figure 5))

$15 \quad(0.8)$

16 for hvile

for rest

rest

( (J rubs his back with right hand, Figure 6))

$17 \quad(0.4)$

18 eller for at fokusere

or for to focus

or to focus 


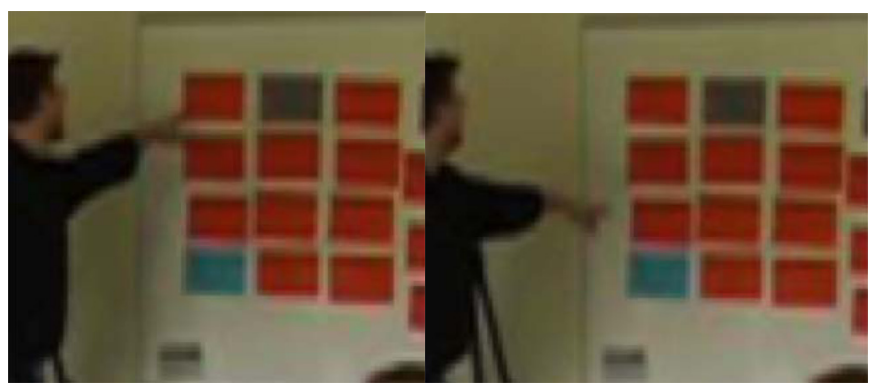

Figures 4 and 5. Jørgen moves to point to another card higher up, and he withdraws his arm

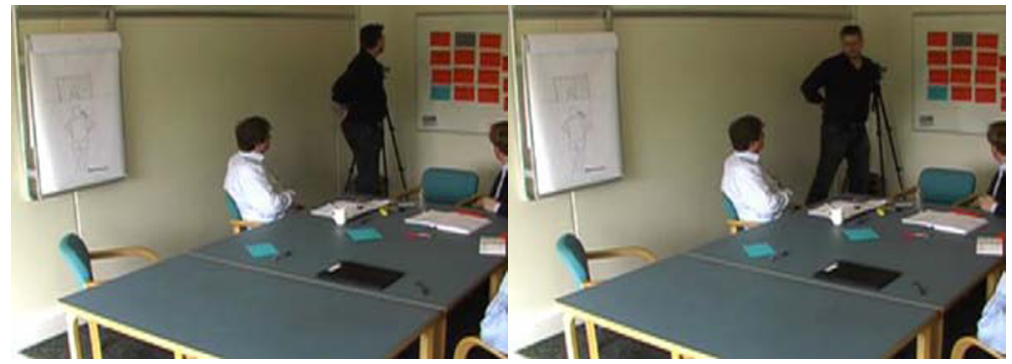

Figures 6 and 7. Jørgen reads aloud, and he turns to face the group

19

(1.0)

( ( $\mathrm{J}$ moves a step back to the wall, J faces the group, scans the faces, Figure 7))

$20 \mathrm{~T} \quad \mathrm{ja}$

yeah

$21 \quad(0.5)$

$22 \mathrm{~J}$ var det dig der skrev den= was it you that wrote it?

( (J looks at $\mathrm{T})$ )

$23 \mathrm{~T}$ =den skrev jeg (for jeg)

=it wrote I (for I)

= that I wrote (for I)

24 (1.3) ((J gazes at whiteboard))

25 T [>>jar sy's jar det] op<<lever af og til i min hverdag [>>I think I it's] experience from time to time in my everyday ( ( $\mathrm{J}$ gazes at $\mathrm{T})$ )

26 når man sidder og ska' fordybe sig i et eller andet when one sits and has to concentrate on something or other 
Now the facilitator focus has shifted from stimulating individual cognitive processes in a silent writing session to looking together at a pool of cards on a whiteboard, each representing a result of individual cognitive work. Thoughts have been turned into neatly arranged cards. Next up is turning cards into talk. In the following, we will see how this is done.

In the first little excerpt the facilitator (Jørgen) gets up and moves towards the whiteboard, picks up the first card, reads it aloud and turns to face the group and identify the card author. But he does more than engage the group in a new activity, which is to form the next part of the exercise. He decides which card to pick, and therefore, which idea to discuss.

Jørgen is about to choose a card, which he shows by pointing at one card, number two from the top in the left row of cards (11. 11-12, Figures 3a and 3b). Then he selects another card by moving his arm to point at another card higher up on the whiteboard, to number one from the top in the left row of cards, and simultaneously begins reading (1. 13, Figure 4). After that he continues reading (1. 14) and withdraws his arm (Figure 5). He pauses while gazing at the card/board (1. 15), and then he continues reading (11. 16-18, Figure 6). Only then does he change his body posture to face the group (1. 19, Figure 7).

The order in which ideas are discussed seems to matter. The facilitator does not randomly pick any card but seems to deliberately choose one card over another as the first to talk about. At this point, the participants do not know if all of the ideas will get to be discussed, or only a selection of them. Neither as a participant at this point in the process, nor as an analyst of the process, will it be possible to determine if it is the best ideas that get to be picked first. But there definitely is an idea selection process with consequences for the interaction and for the group process.

The facilitator uses the cards on the whiteboard to decide topic and timing. He uses the artifacts to select what to talk about first in this part of the exercise where the participants are to turn their written ideas into talk.

The artifacts, however, are not just utilized as resources for interaction. They are made available in advance as a resource for promoting a certain kind of activity. Having the cards carefully arranged in rows on the whiteboard afford such extemporaneous action, making reading 'at a glance' possible (Whalen et al., 2002). He makes the ideas available for topical talk by organizing them in a public display of idea cards in neatly arranged rows and columns. The available pool of cards, each representing an idea/topic, makes it possible for him to select what to talk about and when to talk about it.

\section{Drawing a participant out and eliciting topical talk}

After reading the card aloud, there is a pause in which the facilitator changes his body posture. He turns away from the whiteboard, faces the group and scans their faces (1. 19). By not speaking while gazing at the rest of the participants, the facilitator shows them that something is to come from them, that he is not the one to speak.

Tim seems to self-select in 1. 20, claiming responsibility for the card with a 'yeah'. Jørgen then checks if this was the correct understanding of the 'yeah' (1. 22), which Tim confirms (1.23). Tim being the card author is now the relevant participant to talk about the topic on the card. Tim's self-selecting to speak is, however, not unmotivated. Lerner (2003) has argued how references to items associated with a person can be used to select her/him as the next speaker: 'When the requirements for responding to a sequence-initiating action 


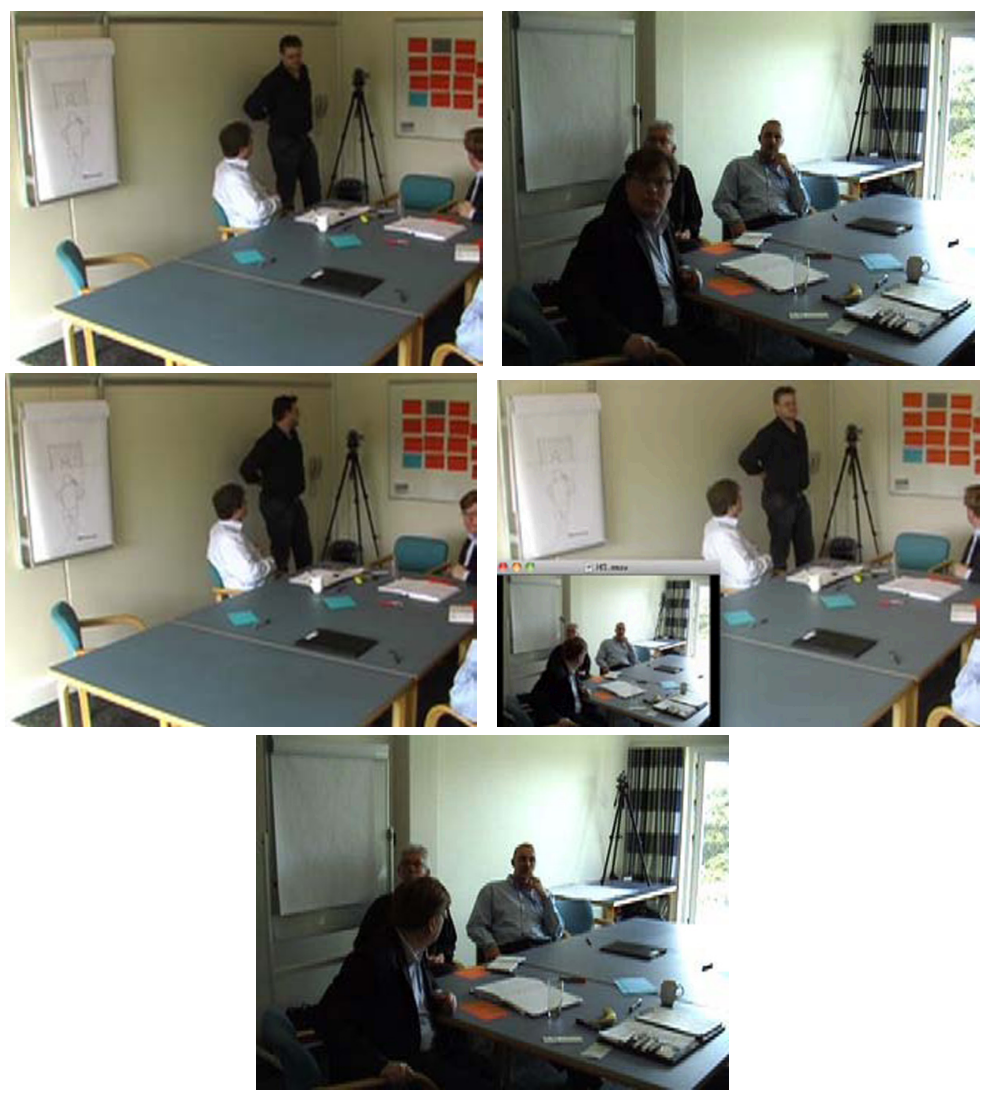

Figures 8-I 2. The I.3 s pause in I. 24: Jørgen looks at Tim, at the whiteboard and back at Tim

limit eligible responders to a single participant, then that participant has been tacitly selected as next speaker.' As seen in the preceding analysis of the facilitator's use of the cards, and as will be shown in the following sections of this paper, the facilitator de facto selected Tim to speak next by picking his card. Jørgen may not at this point know that it was Tim's but Tim does.

The facilitator has instructed the participants to 'mention them' (the ideas), 'put them into words' (11. 6-8). So a distinct slot is now created for Tim as the card author to produce an explanation of his card. And this is exactly what Tim does from 1. 23ff. He begins a turn constructional unit projecting an explanation ('for I') but trails out.

After that a pause as long as 1.3 seconds follows in which Jørgen looks at Tim, the whiteboard and back at Tim (1. 24, Figures 8-12). By not speaking, not producing a receipt or evaluation, and by withdrawing his gaze, Jørgen leaves Tim with the floor.

By returning his gaze to Tim and fixing body position, Jørgen shows him and the rest of the group that claiming responsibility of the card is not the sole purpose of picking a card; more talk is to be produced by Tim as card author. He shows it to be relevant for Tim 
to continue speaking, and since the card text is made relevant as topic by being read aloud, the theme from the selected card is the topic pending for the card author to relate to. Right after Jørgen returns his gaze to Tim, Tim begins to explain the card (1. 25ff.) and Jørgen fixes his gaze on him during the continuation of the explanation. Tim is encouraged to continue by Jørgen (not shown here) until he produces a sort of conclusion in 11. 41-6.

The facilitator focuses his attention on making the card author speak about the card, and does not shift to other activities until having succeeded with that endeavor. The card is read aloud, the card owner identified and the card is explained. This corresponds with a basic technique of 'drawing people out', which is to paraphrase the participant's statement and follow up with open-ended, nondirective questions (Kaner et al., 2007: 45). The facilitator uses gaze, pauses, card author identification and continuers to elicit talk from the card author.

\section{Securing progression, speaker transition and shift in participant identity}

Previously, it was shown how cards on a whiteboard could be used by the facilitator to select topic and timing, to draw a participant out, engage him in topical talk and explain his idea. Next, we will see how the facilitator uses the whiteboard and colored cards to secure progression of the activity and to manage speaker transition. Only when the facilitator has succeeded in having a participant explain his idea does he turn his body to consult the whiteboard again in order to select a new card and a new speaker. Exiting from interacting with one participant makes it possible to make a shift to drawing out another participant. The use of cards is again central in this process. See this next excerpt, which is the continuation of the end of the card explanation begun in extract 1. Tim has been explaining his idea about avoiding noise when this happens.

\section{Extract 2: A2 Finding files}

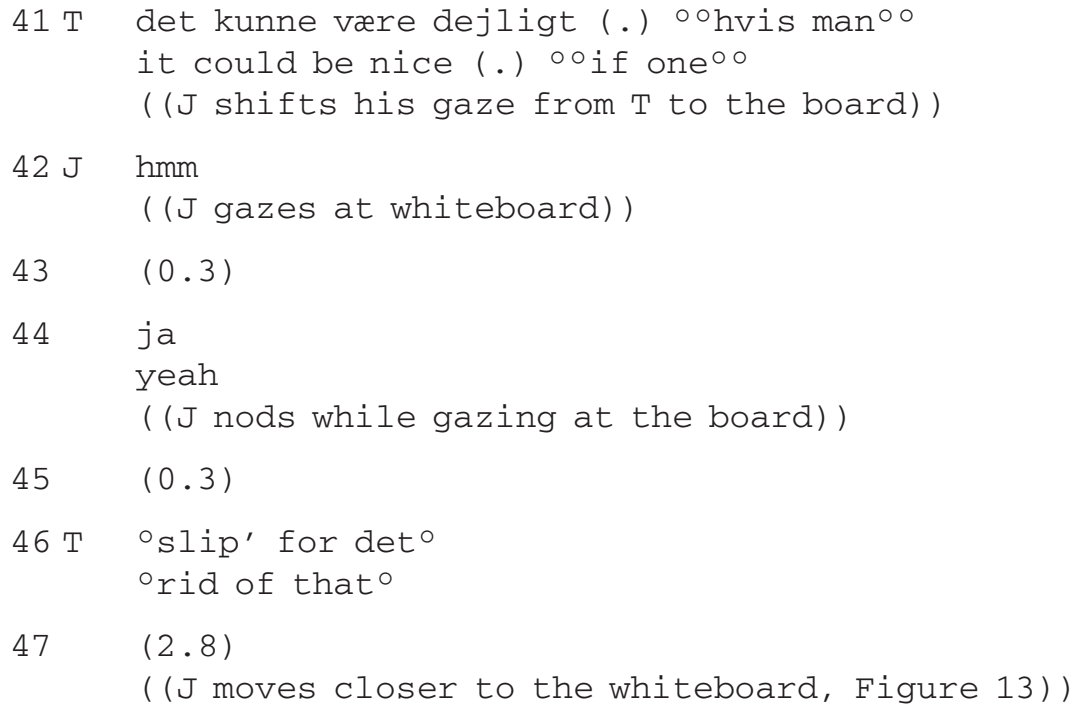




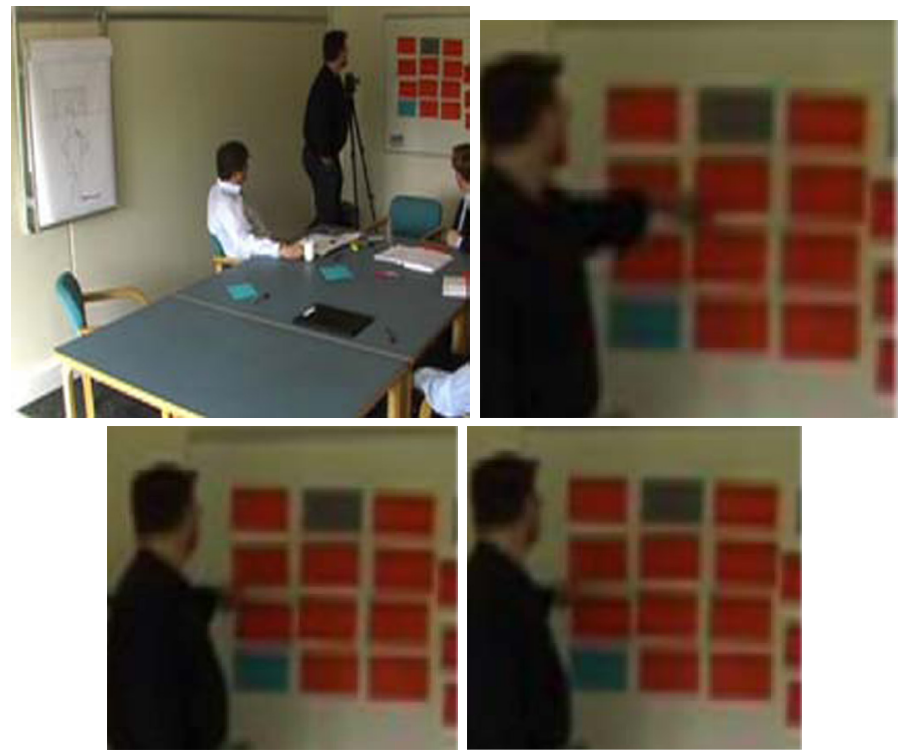

Figures 13-16. J. turns to whiteboard; points at a card; withdraws slightly; points to another card

$48 \mathrm{~J} \quad$ (ska' vi 个ta' den der), (should we $\uparrow$ take this), ( (left arm forward, points at a card, right hand in pocket, Figure 14))

$49 \quad(0.8)$

((moves finger, Figure 15))

$50 \mathrm{~J}$ her har jeg skrevet, here have I written, here I have written, ((moves finger to another card, Figure 16))

51 个NA jo,

$\uparrow \mathrm{OH}$ yes,

$52 * e: h,(h)$

((moves away from the whiteboard, Figure 17))

53 (.)

54 jeg $\uparrow$ ved ikke om de:t en $\phi \mathrm{h}$, I $\uparrow$ don't know if it is a eh, ((moves towards the wall while gazing at the board))

55 problem $\uparrow a l l e$ steder, problem $\uparrow$ everywhere, ((faces the group, Figure 18)) 


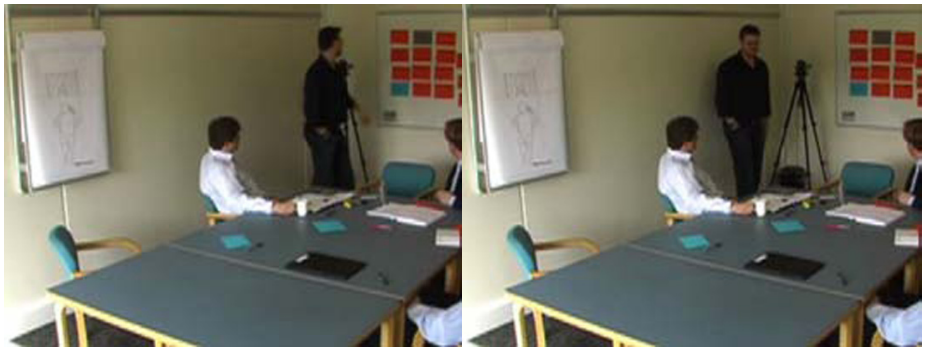

Figures 17 and 18. Jørgen withdraws from the whiteboard; turns to face the group

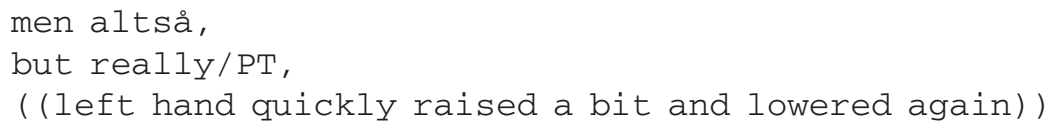

syns jeg bruger 个meget tid på at finde filer, think I spend a $\uparrow$ lot of time finding files,

This second excerpt is from when Tim as the card author of the first card is finishing his explanation of his card (see extract 1). He begins to produce a sort of conclusion (1. 41), seeming to be about to finish his explanation. This could be topic bounding and make it relevant to close (Button, 1987; Schegloff and Sacks, 1973) the talk about this particular card. At that exact point, Jørgen shifts his orientation from the speaker to the whiteboard (11. 41-4), producing minimal responses to Tim $(1.42,44)$ while gazing at the whiteboard. He acknowledges the idea but does not evaluate it, nor does he make it relevant for the group to discuss it. After Tim seems to have finished talking (11. 46-7), reaching turn construction unit completion and speaking in low volume, a long pause appears. At this point, Jørgen moves closer to the whiteboard (1. 47, Figure 13), appearing to have his full attention on the whiteboard. By turning away from Tim, when he is recognizably topic bounding, Jørgen shows Tim as card author that he has produced sufficient talk about the card and will no longer be expected to have the floor.

The whiteboard and cards are now used to secure progression and transition, and to elicit certain social actions from the participants. The facilitator uses the artifacts to move from one speaker to another, from one topic to another, and to move on in the process of working their way through the ideas made available, all representing pending talkables. The cards are used to secure progression in the group activity, and to decouple the presentation of an idea from the discussion of it. Some social actions are encouraged (explaining and accounting for ideas) and other actions are suppressed (discussing and assessing ideas).

Jørgen turns to the whiteboard (1. 47, Figure 13), and again he is about to choose one card (1. 48, Figure 14), but he then withdraws slightly (1. 49, Figure 15), moves to select another (1. 50, Figure 16), this time his own card (11. 50-1). He then withdraws from the whiteboard (Figure 17) and turns to face the group (Figure 18).

Now the cards on the whiteboard are not only used for topic selection, but also for speaker selection. He abandons one of the participant's cards in order to move on to one 
of his own cards. He seems to select the card at the same time as he identifies his own handwriting. Only later does he recognize the idea/topic written on the card, which is evidenced by the change-of-state marker (Heritage, 1984) communicating 'now it's coming back to me' (1. 51).

He is drawing himself out as participant, using local turn types to shift from doing being a facilitator of the social process of developing ideas to doing being a participant in the social process of developing ideas (see Zimmerman, 1998). He makes this shift by using his embodiment of the facilitator role to select himself to be the next card author to talk about his card (11. 47-50), and then as card author begin talking about his card (1. $51 \mathrm{ff}$.).

This time he does not read it aloud, but goes on to account for the card (1. $52 \mathrm{ff}$.). He distances from the card while at the same time taking responsibility for it. It is interesting to see how he still treats the card as something that connects to individual cognitive processes, which need to be explained and accounted for in the group setting.

As a facilitator of the process, Jørgen does not have to participate himself. However, he already entered the idea development process when he sat together with the group writing cards. At that point his participation could merely serve to show engagement in the process instead of waiting for the group to finish writing. It is possible that he decides to pick his own card as the second card to talk about in order to make the others feel at ease with the activity by putting himself in the spotlight too, helping them save face (Goffman, $1967 / 1955)$, or as an attempt to expand the idea range and show idea diversity already present in the group. In this respect it would still be an example of facilitator orienting to topical content in the process; therefore appearing to organize more than turn-taking and activity/process.

In this excerpt it is evident how the facilitator uses the whiteboard to make a shift or secure progression by orienting to the whiteboard when a prior sequence or activity is recognizably winding down. Shifting his bodily orientation back and forth between the whiteboard and the group of participants helps the facilitator create and demarcate speaker transition slots and manage speaker transition. And the cards on the whiteboard are a resource for the facilitator in selecting topic and next speaker. He uses the same technique for drawing himself out and to shift speaker identity in the process as he does for drawing other participants out. Likewise, he uses the multimodal orientation to the artifacts in order to shift speaker identity in the process back to being facilitator, when he (extract 3) only acknowledges Tim's contribution before he moves on to pick the next card (11. 85-91).

\section{Speaker selection and warning}

Above, choosing a card resulted in locating a card author and allocating speakership, and in creating a transition for that participant to go from listener to speaker or from idea development facilitator to idea contributor. A similar use for the facilitator of the whiteboard and colored cards is the other way round: getting a particular participant to speak, using the cards to do speaker selection and warning. See this next excerpt, which is from the end of the card explanation begun in extract 2 .

Visible here is the transition from one card to the next, from the second to the third card in the first group exercise using these tools. Lars has been responding to Jørgen's own idea about finding files when this happens: 


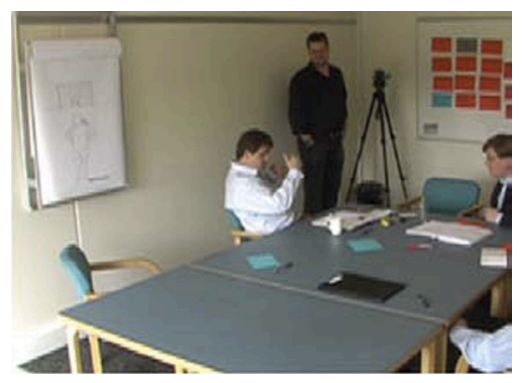

Figure 19. Lars accounts for his card

\section{Extract 3: A3 Multi plug}

$85 \mathrm{~L} \quad>$ vi ved å vend' den< godt

$>$ we're about to turn it around $<$ well

( ( $J$ shifts gaze to whiteboard))

$86 \quad(1.6)$

( ( $J$ moves closer to the whiteboard, left hand forward))

$87 \mathrm{~J} \quad \circ \mathrm{ja} \circ \mathrm{o}$

o yeahoo

$88(0.8)$

89 ? $\quad 0 * \mathrm{mh}^{\circ}$

$90 \quad(0.5)$

( ( $\mathrm{J}$ points at a card))

91 J så den der

then this here

92 个centertilbagemeldinger fra kroppen, 个center feedback from the body,

$93($.

94 for eksempel *blodtryk >sved hjêr<terytme,

for instance *blood pressure >sweat heart< rhythm

$95 \quad(2.2)$

( ( $\mathrm{J}$ moves away from whiteboard, turns toward the group, gazes at $L)$ )

96 L $\uparrow j a h$,

个yeah,

97

(0.4)

( ( $J$ shifts gaze from L to the whiteboard)) 
In the third extract Jørgen quickly chooses a card and allocates a speaker turn. This time he seems to recognize the author of the card (11.91-5), since he picks a card, reads it aloud and turns his gaze to a specific participant. He uses his gaze to address Lars as the card author and allocate a turn to him. Recognizing a specific workshop participant by his handwriting may have been possible for the facilitator of this group since the two of them sat next to each other at the table when writing the cards (Figure 1).

It is not possible as an analyst to determine if this was indeed the intention of the facilitator before turning to the whiteboard, so that he chose a particular card in order to have that particular participant speak, or if he chose the card first and then just happened to recognize the card author. Therefore, it is also not possible to say if he chose to draw out Lars, in spite of Lars having just had a turn at talk, because Lars did not align with his own situation of having a hard time finding files. Either way, the point is that the facilitator uses embodied orientation to artifacts to select a speaker.

In this excerpt it is not only observable how the facilitator uses his multimodal orientation to a range of semiotic resources (whiteboard, colored cards, body posture, gestures, gazes, pauses and talk) to perform speaker selection, since a potential recognition of a card or a person's handwriting may help him use a card to select a specific next speaker; the facilitator also uses the whiteboard to do informing and warning, when he reads the card aloud and shows which topic to orient to next, and implicitly warns the card author to be ready to talk.

\section{Socializing participants to participation framework}

The fact that reading a card aloud serves as a warning of upcoming speakership has to do with socialization. Until 1. 90 in extract 3, the group has been through the process of explaining cards twice. In the first two run-throughs of the cards-on-the-whiteboard exercise (extracts 1 and 2), the facilitator socializes the participants into a particular participation framework (Goffman, 1981). He is beginning to build a local community of practice, involving some collective of people participating through mutual engagement in some joint enterprise encompassing some framework of doing, while developing a shared repertoire of resources (Wenger, 1998). It is through the repeated participation in mutual practices with social negotiation of meaning that members become members and develop shared repertoires of resources.

This shows in the fact that Lars as the card author seems to know what to do next. When Jørgen picks his card (11. 90-4) and turns to gaze at him (1. 95), Lars confirms (1. 96) and projects a long turn with a hypothetical situation about to be explained (11. 98-9). 
By taking responsibility for his card and beginning to explain it, Lars also shows Jørgen to be right in suggesting him to be the card author. Once Lars has taken responsibility for explaining the card by taking a turn (1.96), Jørgen again shifts his orientation to the whiteboard (1.97), having accomplished eliciting card author talk. After having consulted the whiteboard, perhaps planning which card to pick next, Jørgen again turns his attention to Lars by moving his gaze in his direction (11. 97-100). A pattern now shows in orienting to the cards on the whiteboard as a pool of potential topics to pick in the process of turning the written ideas into talk. The script is recognizable for the participants in a fashion that makes it easy for them to fill their role in it when they get the cue.

\section{Eliciting certain social actions: Explanations and accounts}

In focus in this article was a workshop process element organized in seven procedural steps: 1) participants are encouraged to write ideas on colored cards; 2) participants are instructed to hang their colored cards on a whiteboard; 3) a card on the whiteboard is selected for talk by the facilitator; 4) the author of the card is identified; 5) the card author explains his/her card; 6) the facilitator validates the explanation; 7) the next card is selected for talk. The exercise seems to be designed to create explanation slots for the participants to fill with explanations. The facilitator uses this whole machinery to elicit certain social actions: explanations and accounts.

Standing on the shoulders of Pomerantz (1980), Levinson (1983) and Heritage (1988), Antaki shows how a dispreferred or unexpected second pair part may make an explanation relevant, and that non-deliverance of such an explanation may be noticeably absent, and an 'explanation slot' (1994: 78f) may be created. 'A speaker can call for an explanation, or can signal that he or she is about to give one' (p. 68). Antaki distinguishes between self-initiated explanation slots and other-initiated explanation slots.

According to Antaki, explanations 'orientate to problematic information, position or status in people's interaction with each other' (1994: 76), a 'very local unexpected omission or commission' (p. 88). The explanations that fill explanation slots 'deal with the kind of offense which comes up within the borders of the local interaction: to explain, justify or warrant a puzzle which has arisen then and there, and which needs to be sorted out before proceedings can be resumed' (p. 75). These offenses are, according to Antaki, dispreferred conversational moves.

The core process of transferring individual cognitive processes to words on a colored card and hanging the card on a whiteboard makes it possible for others to treat the otherwise hidden thoughts of other people as something to make a 'noticing' of and have the idea owner claim responsibility for (see Nonaka and Takeuchi, 1995).

Moreover, the explanation slots after the card reading constitute an improvised, locally decided agenda consisting of keywords to unfold, similar to what can be seen after agenda items in meeting data. The use of cards/sticky notes can also be considered probes. The card texts being underspecified make them insufficient information, something to be sorted out, and therefore problematic and accountable.

'Noticings' can be phrased in a number of ways (Bergmann, 1992), and they can perform social actions other than inform about observations (Schegloff, 1988); for instance they 
may work as accusations. A 'noticing' may open a slot to be filled with an account (Antaki, 1994: 76; Schegloff, 1988).

Reading the card aloud can be seen as a way of 'fishing' or 'telling my side' of the idea (Pomerantz, 1980), the version of the idea which is visible and available to the interlocutor, and doing this as a prompt to the author to tell his or her side, to explain what is not available on the card. The facilitator turns himself into the animator of the card, which somebody else has been the author of (Goffman, 1981). The puzzle to solve is the words written on the cards, unfolding their rationale and potential as an idea for the group to develop further by 'putting them into words'. An explanation slot is created in the shape of a collaboratively created puzzle to be collaboratively solved or sorted out. A piece of information is deliberatively produced in an insufficient manner, and therefore made potentially problematic, needing explanation.

According to Pomerantz, explanation slots opened by 'noticings' tend to state something redundant requiring explanation (Pomerantz, 1980). By identifying the card author, by pausing and gazing at the card author, the author is made to treat the card as accountable (see Antaki, 1994: 85). Often, the explanation slots in the data are filled with storied accounts (see Antaki, 1994: 92f).

Transferring complex individual cognitive processes to a few words on a colored card entails compressing and under-specifying an idea, partly in order to make it fit the card, and partly perhaps because of the instruction of producing as many cards as possible in a limited amount of time (they have 20 minutes for the whole exercise, including talking about the cards). The constraint in time and space makes it necessary to condense, compress and underspecify. And the mere under-specification (Bergmann, 1992) of the idea makes it relevant to unfold it, to expand it, to explain it, to account for it. Collaboratively created puzzles are constructed in order for them to be sorted out. Explaining an idea may lead to discussing the idea and a group process development of it - the very purpose of such an exercise.

\section{Facilitating brainstorming by separating participant actions in phases}

The reduction and specialization of practices constitutive of the form of brainstorming session identified in this article contribute to the institutional aims they are designed to produce. The facilitator's episodic management of opportunities to speak shape which actions get produced (explaining and accounting for ideas), and which actions or sort of actions specifically get suppressed (assessing ideas). The organization of the meeting into a series of phases that separate the generation of ideas, the presentation of ideas and the subsequent discussion and evaluation of ideas constitute this as a brainstorming session. The specific material objects contribute to these institutional aims. The use of physical objects, such as cards, to record, post and then discuss ideas is central to the interaction. Alternatively, they could have written them together on a whiteboard or a flipover, and the facilitator could have prompted them to produce ideas that he could write on such material objects. In that case, the participant would have interacted verbally while generating ideas; now they are interacting non-verbally but with focus on producing as many cards as possible individually. This corresponds with studies showing that a group process may reduce the speed of contribution and the contribution frequency of individual participants, and 
that participants' mental capacity may not be able to both hold their own ideas and listen to others' ideas, leading to the loss/waste of many potential ideas (Diehl and Stroebe, 1987; Taylor et al., 1958). Separating the generation of ideas from the discussion of them could lead to more diverse ideas produced as well as a greater volume of initial ideas. Therefore, just any form of writing may not accomplish the same ends with respect to making it possible for the otherwise hidden thoughts of people to be available for use by others.

This mechanism for the proposal and selection of ideas for discussion has several consequences. By decoupling the activities of accepting/rejecting (or otherwise evaluating) ideas from the occasion of proposing and recording them, the activity of 'brainstorming' is facilitated (indeed is constitutive of it) because it enables ideas to be developed without any immediate concern for their adequacy or acceptance by others. This stands in contrast to contributions to ordinary conversations in which, as Goffman (1967/1955: 37) notes: 'By saying something, the speaker opens himself up to the possibility that the intended recipients will affront him by not listening or will think him forward, foolish, or offensive in what he has said.' The use of writing - as opposed to talk - as the basis for generating ideas frees the participants from a need to be concerned with what others will say next (and by the same token, having to say something next when an idea is proposed). In effect, using writing (which creates a record that can be drawn on later) does not place the same demands on other participants to listen to or register ideas as they are produced. Many participants can produce ideas simultaneously in parallel courses of action.

At the same time, because this process (of writing ideas on cards) produces a durable public record of the ideas, and these can be displayed to make all of them viewable simultaneously, the facilitator can organize the discussion of individual ideas through a process of 'selection' as opposed to 'rejection'. That is, where ideas are suggested and discussed one-at-a-time (as would be the case in ordinary conversation), the rejection of some subset of ideas is a necessary feature of discussing multiples of them since the parties must close a discussion of one idea before the next one can be introduced. In the method used on this occasion, selection is highlighted over rejection. Though ideas must be discussed, and those discussions closed to make room for the discussion of other ideas, it is not necessary to do this for each idea as it is proposed because only a subset of ideas may be selected for discussion. To be sure, ideas can be critiqued once they are selected, but many of the proposed ideas may not be discussed at all, saving their authors the fate of having them rejected (and thus the anticipatory filtering that is otherwise characteristic of real-time conversation).

By physically recording the ideas there is also a potential diminishment of the producer's ownership rights to it. Others can appreciate ideas, or comment on them, without necessarily implicating disagreement with the persons who proposed them. More generally, recording ideas on cards enables them to be used in a range of ways disengaged from the site of their production.

In a variety of ways, then, the organization of the meeting into phases (that separate the generation of ideas from their discussion), the recording of ideas on cards that can be arranged and rearranged, and the use of a facilitator to select ideas for discussion has two main consequences: first, it enables ideas to be generated freely by all participants while diminishing the need for producers to be concerned with how others might react to or receive ideas; second, the discussion of ideas (once they are generated) favors idea selection over idea rejection as the central activity of the meeting. 


\section{Conclusion}

Social idea development process facilitation is very much a matter of cognitive, bodily and material orientation. This article has shown how 'doing facilitation of brainstorming' consists not only of organizing group activities, chairing a group meeting and managing turn-taking, but also consists to a high degree in forcing each group member to participate actively and contribute to the specific activity type (Levinson, 1992), a group process of brainstorming, and in creating the preliminaries of a potential local community of practice. It was evidenced how multimodal orientation to a range of semiotic resources (whiteboard, colored cards, body posture, movement, direction, gestures, gazes, pauses and talk) was used to organize topical talk, manage speaker transition and secure both progression and shifts necessary to produce the desired activity type. A facilitator may very actively shape the process by orchestrating participant input. This questions the facilitator role as 'content neutral', as proposed by leading professionals in the field (e.g. Kaner et al., 2007: xv).

The facilitator used artifacts to help participants produce ideas and make them visible to the group, turning ideas and cognitive processes into 'talkables' available for the group to address. The artifacts helped them both validate individual cognitive processes and go from individual cognitive processes to social group processes. By creating a silent space for writing ideas on cards, the facilitator stimulated cognitive processes. By instructing participants to jot down key words, the facilitator helped participants document cognitive processes, crystallize ideas, remember ideas produced and let ideas move from off-record to on-record by encouraging individual selection of ideas to share with the group. Artifacts were used to help participants communicate individual thoughts to the group, make ideas visible to others, by making silent interaction between ideas possible, and by making it possible for the group to focus attention and gather around a mutual focus point. The facilitator thus helped participants communicate group process results within the group, turning individual cognitive output into group process product and document group process results.

Crucial was the facilitator's role in eliciting talk from participants, in performing shifts in participants' local speaker identity (from recipient to speaker and idea producer), in generating more ideas and saving face by decoupling actions and activities (separating the production of ideas from the discussion) and in eliciting particular social actions (explanations and accounts) from participants. Drawing participants out in order for them to participate in the process and share their knowledge and ideas with co-participants was shown to be an embodied, multimodal social practice.

Process facilitation may be seen as doing leadership with an emphasis on distribution of participation, a subtle way of steering participants in a particular direction, specifying concrete mechanisms through which their deployment produced 'brainstorming' as an institutional activity. As such, innovation workshop facilitation may socialize the participants into a particular participation framework, letting them collaborate in shaping a local community of practice of using artifacts to organize talk. The presence of a facilitator makes it possible for participants to decouple the sequential order they would ordinarily orient to, thus furthering particular institutional aims.

\section{Acknowledgments}

Thanks are due to Brian Due, Gitte Gravengaard, Magnus Larsson, Lorenza Mondada, Sae Oshima, Jan Svennevig and anonymous reviewers for fruitful comments on earlier versions of this article. 


\section{References}

Amabile TM (1996) Creativity in Context. Boulder, CO: Westview Press.

Antaki C (1994) Explanation slots. In: Explaining and Arguing: The Social Organization of Accounts. London, Thousand Oaks, CA and New Delhi: SAGE.

Bergmann J (1992) Veiled morality: Notes on discretion in psychiatry. In: Drew P and Heritage J (eds) Talk at Work: Interaction in Institutional Settings. Cambridge: Cambridge University Press, 137-162.

Button G (1987) Moving out of closings. In: Button G and Lee JRE (eds) Talk and Social Organisation. Clevedon: Multilingual Matters Ltd, 101-151.

Campbell D (1960) Blind variation and selective retention in creative thought as in other knowledge processes. Psychological Review 67(6): 380-400.

Cooren F, Thompson F, Canestraro D and Bodor T (2006) From agency to structure: Analysis of an episode in a facilitation process. Human Relations 59(4): 533-565.

Diehl M and Strobe W (1987) Productivity loss in brainstorming groups: Towards the solution of a riddle. Journal of Personality and Social Psychology 53: 497-509.

Drew P and Heritage J (eds) (1992) Talk at Work: Interaction in Institutional Settings. Studies in Interactional Sociolinguistics 8. Cambridge: Cambridge University Press.

Goffman E (1967/1955) On face-work: An analysis of ritual elements in social interaction. In: Interaction Ritual. New York: Anchor Books, 5-45. Reprint of Goffman E (1955) Psychiatry XVIII: 213-231.

Goffman E (1981) Forms of Talk. Philadelphia: University of Pennsylvania Press.

Goodwin C (1981) Conversational Organization: Interaction between Speakers and Hearers. New York: Academic Press.

Goodwin C (1994) Professional vision. American Anthropologist 96: 606-633.

Goodwin C (1997) The blackness of black: Color categories as situated practice. In: Resnick L, Säljö R, Pontecorvo C and Burge B (eds) Discourse, Tools and Reasoning: Essays on Situated Cognition. New York: Springer-Verlag, 111-140.

Goodwin C (1999) Practices of color classification in professional discourse. In: Jaworski A and Coupland N (eds) The Discourse Reader. London and New York: Routledge, 474-491.

Goodwin C (ed.) (2003) Conversation and Brain Damage. Oxford: Oxford University Press.

Goodwin C (2007) Participation, stance and affect in the organization of activities. Discourse \& Society 18(1): 53-73.

Goodwin C and Duranti A (eds) (1992) Rethinking Context: Language as an Interactive Phenomenon. Cambridge: Cambridge University Press.

Goodwin C and Goodwin MH (1996) Formulating planes: Seeing as a situated activity. In: Middleton D and Engeström Y (eds) Cognition and Communication at Work. Cambridge: Cambridge University Press, 61-95.

Guilford JP (1967) The Nature of Human Intelligence. New York: McGraw-Hill.

Heritage J (1984) A change-of-state token and aspects of its sequential placement. In: Atkinson JM and Heritage J (eds) Structures of Social Action: Studies in Conversation Analysis, Studies in Emotion and Social Interaction. Cambridge: Cambridge University Press.

Heritage J (1988) Explanations as accounts: A conversation analytic perspective. In: Antaki C (ed.) Analysing Everyday Explanation: A Casebook of Methods. Beverly Hills, CA: SAGE, 127-144.

Kaner S, with Lind L, Toldi C, Fisk S and Berger D (2007) Facilitator's Guide to Participatory Decision-making, 2nd edn. San Francisco, CA: Jossey-Bass.

Latour B (1987) Science in Action: How to Follow Scientists and Engineers through Society. Cambridge, MA: Harvard University Press.

Latour B (1988) The Pasteurization of France. Cambridge, MA: Harvard University Press. 
Latour B and Woolgar S (1979/1986) Laboratory Life: The Construction of Scientific Facts. Princeton, NJ: Princeton University Press.

Lerner GH (2003) Selecting next speaker: The context-sensitive operation of a context-free organization. Language in Society 32(2): 177-201.

Levinson SC (1983) Pragmatics. Cambridge: Cambridge University Press.

Levinson SC (1992) Activity types and language. In: Drew P and Heritage J (eds) Talk at Work: Interaction in Institutional Settings. Cambridge: Cambridge University Press, 66-100.

Lopez EC, Esquivel GB and Houtz JC (1993) The creative skills of culturally and linguistically diverse gifted students. Creativity Research Journal 6: 401-412.

Lysklett SR (2007) Dialog mellom ideer. Ideutviklingens vilkår i arbeidsgruppemøter. Dr.avhandling. NTNU; Institutt for språk- og kommunikasjonsstudier.

Mondada L (2003) Working with video: How surgeons produce video records of their actions. Visual Studies 18(1): 58-72.

Mondada L (2011) The interactional production of multiple spatialities within a participatory democracy meeting. Social Semiotics 21(2): 283-308.

Nijstad BA, Stroebe W and Lodewijkx HFM (2002) Cognitive stimulation and interference in groups: Exposure effects in an idea generation task. Journal of Experimental Social Psychology 38: 535-544.

Nonaka I and Takeuchi H (1995) The Knowledge-creating Company: How Japanese Companies Create the Dynamics of Innovation. New York: Oxford University Press.

Norman D (1993) Things that Make Us Smart. Reading, MA: Addison Wesley.

Osborn A (1953) Applied Imagination: Principles and Procedures of Creative Problem Solving. New York: Charles Scribner \& Sons.

Pomerantz A (1980) Telling my side: 'Limited access' as a 'fishing' device. Sociological Inquiry 50: 186-198.

Runco MA (1998) Creativity as interpretation. In: Russ SW (ed.) Affect, Creative Experience and Psychological Adjustment. Brunner Mazel: Taylor \& Francis Group.

Schegloff EA (1988) Goffman and the analysis of conversation. In: Drew P and Wootton A (eds) Erving Goffman: Exploring the Interaction Order. Cambridge: Polity, 89-135.

Schegloff EA and Sacks H (1973) Opening up closings. Semiotica 8(4): 289-327.

Sidnell J (2005) Multimodal Interaction. Berlin: Mouton de Gruyter.

Simonton D (1999) Origins of Genius. New York: Oxford University Press.

Stevens GA and Burley J (1997) 3000 raw ideas = 1 commercial success! Research \& Technology Management 40(3): 16-27.

Stivers T and Sidnell J (2005) Introduction: Multimodal interaction. Semiotica 156(1/4): 1-20.

Streeck J (1993) Gesture as communication I: Its coordination with gaze and speech. Communication Monographs 60: 275-299.

Streeck J (1996) How to do things with things: Objets trouvés and symbolization. Human Studies 19: $365-384$.

Sutton R (2002) Weird Ideas that Work. New York: Free Press.

Taylor DW, Berry PC and Block CH (1958) Does group participation when brainstorming facilitate or inhibit creative thinking? Administrative Science Quarterly 3: 23-47.

Wenger E (1998) Communities of Practice. Cambridge: Cambridge University Press.

Whalen J (1995) A technology of order production: Computer-aided dispatch in public safety communications. In: Psathas G and ten Have P (eds) Situated Order: Studies in the Social Organization of Talk and Embodied Action. Washington, DC: University Press of America.

Whalen J, Whalen M and Henderson K (2002) Improvisational choreography in teleservice work. The British Journal of Sociology 53: 239-258.

Zimmerman DH (1998) Identity, context and interaction. In: Antaki C and Widdicombe S (eds) Identities in Talk. London: SAGE, 87-106. 
Mie Femø Nielsen, $\mathrm{PhD}$, is Associate Professor in the Department of Scandinavian Studies and Linguistics at the University of Copenhagen. She has written several books on strategic communication and professional interaction; edited and co-edited a number of books and special issues of peer reviewed journals; and published papers in a number of peer reviewed journals and edited collections in English and Danish. 